J. Clin. Chem. Clin. Biochem.

Vol. 25, 1987, pp. 845-853

(C) 1987 Walter de Gruyter \& Co.

Berlin - New York

\title{
Monoethylglycinexylidide Formation Kinetics: A Novel Approach to Assessment of Liver Function ${ }^{1}$ )
}

By M. Oellerich, E. Raude

Institut für Klinische Chemie, Medizinische Hochschule Hannover

M. Burdelski

Kinderklinik, Medizinische Hochschule Hannover

M. Schulz, F. W. Schmidt

Abteilung für Gastroenterologie und Hepatologie, Medizinische Hochschule Hannover

B. Ringe, P. Lamesch, R. Pichlmayr

Klinik für Abdominal- und Transplantationschirurgie, Medizinische Hochschule Hannover

H. Raith, M. Scheruhn, M. Wrenger

Institut für Klinische Chemie, Medizinische Hochschule Hannover and

Ch. Wittekind

Institut für Pathologie, Medizinische Hochschule Hannover

Technical assistance:

B. Klawunn, A. Knoke, B. Mues

Institut für Klinische Chemie, Medizinische Hochschule Hannover and

M. Farle

Klinik für Abdominal- und Transplantationschirurgie, Medizinische Hochschule Hannover

(Received September 8/October 24, 1987)

Summary: A novel quantitative liver function test is described which is based on monoethylglycinexylidide (MEGX) formation after lidocaine bolus injection. Following the administration of small single doses of lidocaine hydrochloride ( $1 \mathrm{mg} / \mathrm{kg}$ ), monoethylglycinexylidide serum concentration-time curves were determined by a novel highly sensitive fluorescence polarisation immunoassay (FPIA) in healthy volunteers, liver donors and patients with liver cirrhosis. The FPIA allowed rapid and reliable monoethylglycinexylidide determinations in serum and urine (between-days coefficient of variation: $<10.3 \%$, recovery: $80-113 \%$ ). Monoethylglyci-

\footnotetext{
1 Preliminary results of this study were presented at the Third Meeting of the German Association for the Study of the Liver in Hannover 1987 (Abstracts: Z. Gastroenterologie 25, 1-2 and 79-80 (1987)) and at the International Organ Transplant Forum in Pittsburgh 1987 (1. c. (16)). Supported by the Deutsche Forschungsgemeinschaft Pi 48/11-1.
} 
nexylidide concentrations measured by FPIA in 32 serum samples from patients correlated well those determined by HPLC. The monoethylglycinexylidide concentration in serum determined 15 min after a lidocaine bolus injection proved to be a highly sensitive and specific indicator of hepatic dysfunction. Average monoethylglycinexylidide concentrations in serum obtained 15 min after lidocaine injection were substantially lower in patients with liver cirrhosis than in healthy volunteers. The average monoethylglycinexylidide concentrations in serum were also substantially lower in liver donors with ballooning or fatty changes of hepatocytes than in donors without relevant alterations of liver histology. By means of monoethylglycinexylidide formation in the liver donors, primary function of the transplanted liver was correctly predicted in $32 / 37$ cases and initial non-function in $4 / 6$ cases.

\section{Introduction}

In the past few years, liver transplantation has gained increasing importance for the treatment of liver failure in acute and chronic liver disease. This development has created a great demand for suitable tests for the assessment of liver function particularly in liver allograft donors and recipients.

Assessment of liver function is essential in potential liver donors in order to avoid transplantation of organs with a high risk of initial non-function. Macroscopic appearance, clinical chemical analyte determinations (e.g. aspartate aminotransferase, bilirubin) and common quantitative liver function tests (e.g. indocyanine green (1) or galactose (2) elimination) often fail to provide sufficient prognostic information $(3,4)$. In a previous study Forrest et al. (5) reported that in patients with chronic liver disease elimination of lidocaine was much more affected than that of antipyrine and paracetamol. Therefore these authors concluded that the half-life of lidocaine is a highly sensitive indicator of hepatic dysfunction. Recently it has been suggested that the formation kinetics of the lidocaine metabolite monoethylglycinexylidide (MEGX) could be used in the evaluation of liver function (6).

Lidocaine is metabolized by the liver and only about $3 \%$ of the dose is excreted as intact drug in the urine over 24 hours (7). Monoethylglycinexylidide (fig. 1)

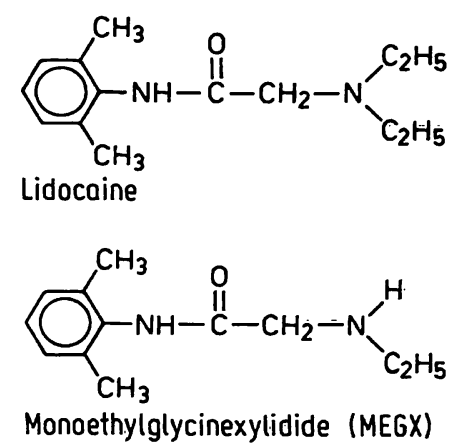

Fig. 1. Structural formulae of lidocaine and monoethylglycinexylidide (MEGX). is formed from lidocaine via oxidative $\mathrm{N}$-deethylation by the hepatic cytochrome P-450 system (8). Monoethylglycinexylidide, which is further metabolized to glycinexylidide and 4-hydroxy-2,6-xylidine, is found only in small quantities (about $4 \%$ of the lidocaine dose) in the urine (7). The pharmacokinetics and pharmacodynamics of monoethylglycinexylidide have recently been studied in healthy subjects (9).

The present study was designed to investigate the clinical usefulness of monoethylglycinexylidide formation kinetics for the assessment of liver function. For this purpose monoethylglycinexylidide serum concentration-time curves were determined by use of a novel highly sensitive fluorescence polarisation immunoassay (FPIA) in healthy volunteers, liver donors and patients with liver cirrhosis. A further aim of the study was to assess the accuracy of the FPIA by comparison with HPLC. Monoethylglycinexylidide concentrations in serum following lidocaine bolus injection were studied for possible correlation with the morphological features of liver grafts.

\section{Materials and Methods}

Study design

Venous blood was taken from 16 healthy volunteers and 13 patients with histologically confirmed liver cirrhosis at $2,5,10$, $15,20,30,60,120,180,240$ and $300 \mathrm{~min}$ after bolus injection of $1 \mathrm{mg} / \mathrm{kg}$ lidocaine hydrochloride (Xylocaine solution $20 \mathrm{~g} / \mathrm{l}$; Astra Chemicals, Wedel, F. R. G.). During the first hour after lidocaine injection the healthy volunteers and the patients were in a recumbent position. Urine samples were collected at intervals of $3 \mathrm{~h}$ over a period of $24 \mathrm{~h}$. In addition, the $15 \mathrm{~min}$ monoethylglycinexylidide concentrations in serum were determined in 12 fully rehabilitated liver recipients, who had survived liver transplantation for 1 to 12 years. Test subjects participated in the study after giving written informed consent.

In 48 liver donors with confirmed brain death, resulting from head injury or intracranial haemorrhage, blood was taken before as well as 15, 30 and $60 \mathrm{~min}$ after an intravenous lidocaine (Xylocaine $\left.{ }^{(}\right)$bolus injection $(1 \mathrm{mg} / \mathrm{kg})$. The investigations on monoethylglycinexylidide formation kinetics were part of a collaborative study on the assessment of donor suitability which was approved by the local Ethics Committee. 


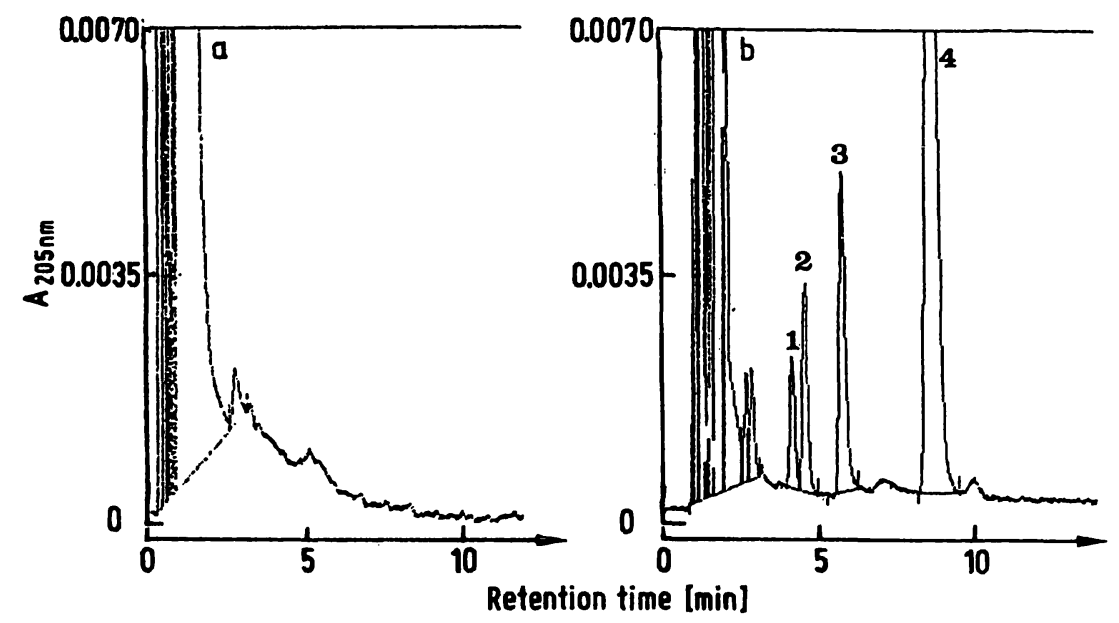

Fig. 2. Chromatograms of extracts from drug-free human serum (a) and from a serum sample of a patient who had received a lidocaine bolus injection (b). Peaks: glycinexylidide (1); tocainide, internal standard (2); monoethylglycinexylidide (3); lidocaine (4).

\section{Materials}

The reagents for the fluorescence polarisation immunoassay (FPIA) were provided for investigational use by Abbott Laboratories (North Chicago, U.S. A.). Monoethylglycinexylidide hydrochloride, lidocaine hydrochloride, glycinexylidide hydrochloride, 4-hydroxy-2,6-xylidine hydrochloride and tocainide hydrochloride were a generous gift from Astra Alab AB (Södertälje, Sweden). Triethylamine (Fluka AG, Buchs, Switzerland) or orthophosphoric acid $85 \%$ (E. Merck, Darmstadt, F. R. G.) were of analytical reagent grade. Acetonitrile (Baker, GroßGerau, F. R. G.) was of HPLC grade. All other chemicals were purchased from E. Merck (Darmstadt, F. R. G.).

\section{Fluorescence polarisation immunoassay (FPIA)}

Monoethylglycinexylidide determinations in serum or urine were carried out by fluorescence pclarisation immunoassay (Abbott Laboratories, North Chicago, U.S. A.) using the TDx Fluorescence Polarisation Immunoassay System according to the instructions of the manufacturer. In a slight modification of the original procedure (19) calibrators were used, which contained monoethylglycinexylidide concentrations of 25 to 250 $\mu \mathrm{g} / \mathrm{l}$. Standard solutions were prepared by dissolving $23.34 \mathrm{mg}$ monoethylglycinexylidide hydrochloride in $200 \mathrm{ml}$ water (relative molecular mass of monoethylglycinexylidide: 206.16). One $\mathrm{ml}$ was diluted with water to $100 \mathrm{ml}$. This solution $(1000 \mu \mathrm{g} / \mathrm{l})$ was further diluted $1+3,1+4.7,1+9,1+19$ and $1+39$ with monoethylglycinexylidide-free human serum, yielding the following monoethylglycinexylidide concentrations: 250,175 , 100,50 and $25 \mu \mathrm{g} / \mathrm{l}$. Pure serum was used as zero calibrator.

Detection limit of fluorescence polarisation immunoassay

A series of 20 zero calibrator samples was analysed by fluorescence polarisation immunoassay. The mean and standard deviation of the observed fluorescence polarisation values were calculated. The calibration curve was used to determine the monoethylglycinexylidide concentration which corresponded to the fluorescence polarisation obtained by subtraction of the three-fold standard deviation from the mean. In accordance with a definition by Kaiser (11) this value was regarded as the detection limit of the assay.

High performance liquid chromatography (HPLC)

HPLC was performed by a modification of a procedure described by Nation et al. (12). To $1 \mathrm{ml}$ of serum or standard in a glass conical tube were added: $100 \mu$ of internal standard solution $(1.25 \mathrm{mg} / \mathrm{l}$ tocainide in water), $100 \mu \mathrm{l}$ of $1 \mathrm{mmol} / \mathrm{l}$ $\mathrm{NaOH}$, and $3 \mathrm{ml}$ of ethylacetate. The tubes were shaken mechanically for $1 \mathrm{~min}$ (Multivortex), centrifuged at $1000 \mathrm{~g}$ for $5 \mathrm{~min}$, and the upper (organic) phase was transferred into a clean glass conical tube. Then $100 \mu \mathrm{l}$ of $0.01 \mathrm{~mol} / 1 \mathrm{HCl}$ was added, and the tubes were shaken and centrifuged as described above. An aliquot of $40 \mu \mathrm{l}$ from the lower (aqueous) phase was injected into the chromatograph.

The chromatographic system consisted of a Hewlett Packard HP 1090 equipped with an automatic sample injector, a heated oven compartment, a diode-array-detector, and a 3392 A digital integrator. Chromatography was performed on a reversedphase $C_{8}$ analytical column (Hypersil-MOS, $5 \mu \mathrm{m}, 200 \times 4.6$ mm I. D.; Hewlett Packard, Waldbronn, F. R. G.)) at an oven temperature of $40^{\circ} \mathrm{C}$. The diode-array-detector was operated at $205 \mathrm{~nm}$. The mobile phase was a mixture $(30+70$, by vol.) of acetonitrile and a solution ( $\mathrm{pH}: 2.4)$ containing $8.7 \mathrm{mmol} / \mathrm{l}$ orthophosphoric acid plus $7.2 \mathrm{mmol} / 1$ triethylamine. It was delivered under isocratic conditions at a flow rate of $2 \mathrm{ml} / \mathrm{min}$. A chromatogram is shown in figure 2 . Standards were prepared by addition of varying known amounts of monoethylglycinexylidide to monoethylglycinexylidide-free human serum. Standard curves were plotted as the metabolite-to-internal standard peak height ratio versus the concentration of the standard samples. The linear regression line was calculated by the method of least squares (fig. 3).

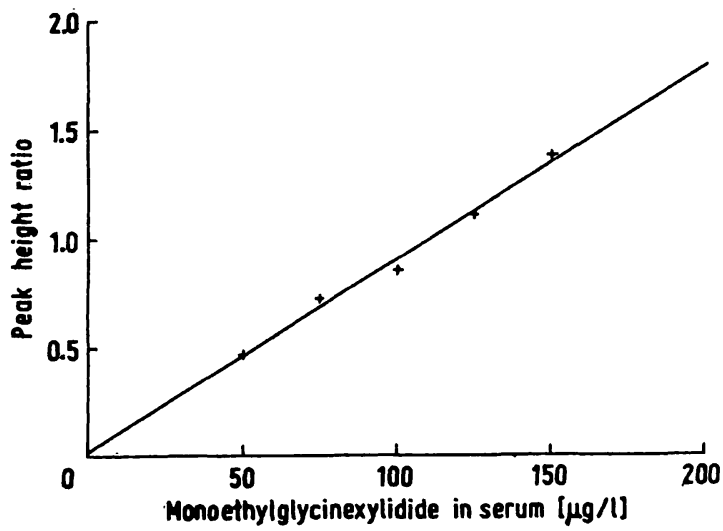

Fig. 3. Calibration curve for the determination of monoethylglycinexylidide in serum by HPLC. Peak-height ratio is defined as: height of monoethylglycinexylidide peak/ height of internal standard peak. 


\section{Statistical analysis}

The statistical evaluation of the results obtained by fluorescence polarisation immunoassay and HPLC was based on the standardised principal component analysis (13) and the significance of the bias $\bar{x}-\bar{y}$ (paired $t$-test). Unless stated otherwise mean values with standard deviation are given. Monoethylglycinexylidide concentrations in serum obtained in healthy volunteers and liver donors $15 \mathrm{~min}$ after lidocaine bolus injection were compared using the unpaired t-test.

\section{Results}

\section{Precision of FPIA and HPLC}

At monoethylglycinexylidide concentrations in serum between 26 and $202 \mu \mathrm{g} / 1$ the within series relative standard deviations ranged from 2.2 to $10.0 \%$ (tab. 1). Spiked human urine samples containing $1000 \mu \mathrm{g} / 1$ monoethylglycinexylidide showed a satisfactory precision with this assay (relative standard deviation: $4.4 \%)$. The urine samples were diluted eleven-fold with TDx system dilution buffer (bovine $\gamma$-globulin in phosphate buffer) before being assayed. Betweendays relative standard deviations of single determinations in serum were 4.5 and $10.3 \%$ at concentrations of 109 and $59 \mu \mathrm{g} / 1$ respectively. With HPLC the within series relative standard deviations of single determinations in serum ranged from 3.2 to $9.2 \%$ (tab. 1).

\section{Accuracy of FPIA}

Average recoveries of monoethylglycinexylidide added to drug-free human serum are shown in table 2. At monoethylglycinexylidide concentrations in serum between 20 and $200 \mu \mathrm{g} / 1$ recovery ranged from 80 to $113 \%$ and 94 to $107 \%$ with FPIA and HPLC respectively. In spiked urine samṕles $(n=2)$ containing 1000 and $3000 \mu \mathrm{g} / 1$ monoethylglycinexylidide, recoveries with FPIA were 112 and $101 \%$ respectively. In addition, monoethylglycinexylidide concentrations in serum, measured by fluorescence polarisation immunoassay, were compared with those determined by HPLC. Serum samples from 32 patients receiving single lidocaine bolus injections were analysed by both methods. As shown in figure 4 both methods correlated well. The monoethylglycinexylidide concentrations in serum obtained by fluorescence polarisation immunoassay were on average about $10 \%$ higher than those determined by HPLC ( $p<0.05$ ).

\section{Specificity of FPIA}

The specificity of the FPIA was assessed by adding lidocaine and major metabolites of this compound to drug-free human serum. No significant cross-reactions were found with lidocaine, glycinexylidide and 4-hydroxy-2,6-xylidine (tab. 3).

Tab. 1. Precision of FPIA and HPLC for the determination of monoethylglycinexylidide (MEGX) in serum.

\begin{tabular}{|c|c|c|c|c|c|c|c|c|}
\hline \multicolumn{3}{|c|}{$\begin{array}{l}\text { FPIA } \\
\text { Precision within series }^{1} \text { ) }\end{array}$} & \multicolumn{3}{|c|}{ Precision between days ${ }^{2}$ ) } & \multicolumn{3}{|c|}{$\begin{array}{l}\text { HPLC } \\
\text { Precision within series }{ }^{1} \text { ) }\end{array}$} \\
\hline $\begin{array}{l}\left.\overline{\mathrm{x}}^{3}\right) \\
(\mu \mathrm{g} / \mathrm{l})\end{array}$ & $\begin{array}{l}\text { SD } \\
(\%)\end{array}$ & $\left.\mathrm{n}^{4}\right)$ & $\begin{array}{l}\left.\overline{\mathrm{x}}^{3}\right) \\
(\mu \mathrm{g} / \mathrm{l})\end{array}$ & $\begin{array}{l}\text { SD } \\
(\%)\end{array}$ & $\left.n^{4}\right)$ & $\begin{array}{l}\left.\overline{\mathrm{x}}^{\overline{3}}\right) \\
(\mu \mathrm{g} / \mathrm{l})\end{array}$ & $\begin{array}{l}\mathrm{SD} \\
(\%)\end{array}$ & $\left.\mathrm{n}^{4}\right)$ \\
\hline $\begin{array}{r}26 \\
40 \\
76 \\
146 \\
202\end{array}$ & $\begin{array}{r}10.0 \\
4.5 \\
5.0 \\
1.9 \\
2.2\end{array}$ & $\begin{array}{l}10 \\
10 \\
10 \\
10 \\
10\end{array}$ & 109 & $\begin{array}{r}10.3 \\
4.5\end{array}$ & $\begin{array}{l}15 \\
15\end{array}$ & $\begin{array}{r}26 \\
54 \\
117\end{array}$ & $\begin{array}{l}9.2 \\
4.0 \\
3.2\end{array}$ & $\begin{array}{r}10 \\
10 \\
9\end{array}$ \\
\hline
\end{tabular}

1) determined with spiked human serum samples

2) determined with diluted control serum (Abbott)

3) mean value $(\bar{x})$ with relative standard deviation (SD \%)

4) number of contributing values

Tab. 2. The recovery of monoethylglycinexylidide (MEGX) by FPIA and HPLC in serum.

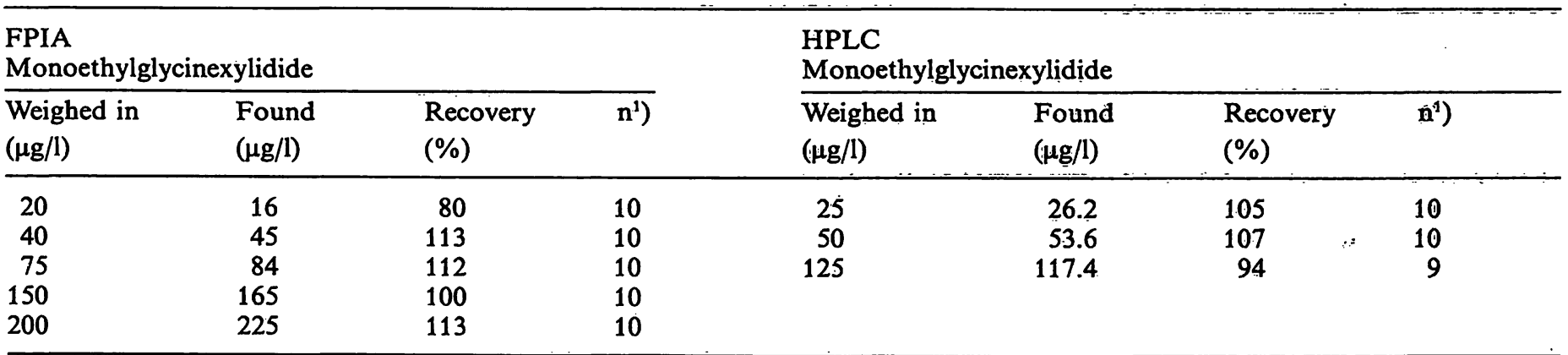

1) number of contributing values 


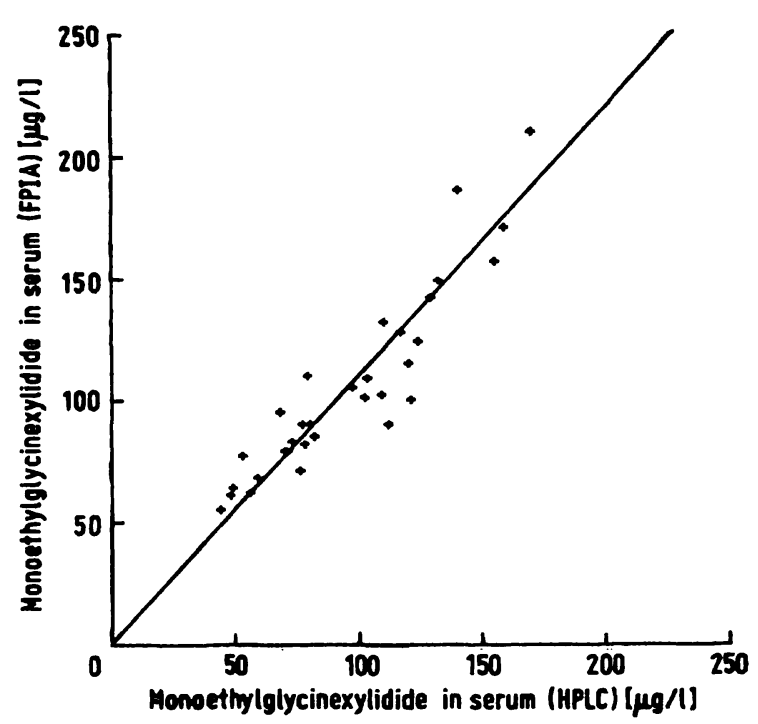

Fig. 4. Monoethylglycinexylidide serum concentrations as measured by HPLC and FPIA in samples from patients $(\mathrm{n}=32)$ receiving single lidocaine bolus injections. $[\overline{\mathrm{y}}=1.10 \mathrm{x}+0.11 ; \mathrm{r}=0.924 ; \overline{\mathrm{x}}(\mathrm{s})=95.7(34.5) \mu \mathrm{g} / \mathrm{l}$; $\overline{\mathrm{y}}(\mathrm{s})=105.4(37.9) \mu \mathrm{g} / \mathrm{l}$.]

Tab. 3. Cross-reactivity of lidocaine and major lidocaine metabolites in serum with the FPIA.

\begin{tabular}{lc}
\hline Compound ${ }^{1}$ ) & $\left.\mathrm{mg} / \mathrm{l}^{2}\right)$ \\
\hline Monoethylglycinexylidide (MEGX) & 0.03 \\
Lidocaine & 43.0 \\
Glycinexylidide & 11.0 \\
4-Hydroxy-2,6-xylidine & $>1000.0$ \\
\hline
\end{tabular}

1) Substances were added to drug-free human serum.

2) Concentration producing a response in the FPIA equivalent to $0.03 \mathrm{mg} / 1$ monoethylglycinexylidide.

\section{Detection limit}

The detection limit for monoethylglycinexylidide was $11 \mu \mathrm{g} / \mathrm{l}$ with the fluorescence polarisạtion immunoasșay.

Monoetbylglycinexylidide concentrations in serum after lidocáine bolus injection

In figures 5, 6 and 7 the formation and elimination kinetics of monoethylglycinexylidide are shown for healthy volunteers, patients with histologically confirmed liver cirrhosis and liver donors after administration of single intravenous lidocaine bolus injections $(1 \mathrm{mg} / \mathrm{kg}$ ). To exclude patients with previous lidocaine therapy, only data from those subjects with monoethylglycinexylidide predose serum concentrations below the detection limit of the fluorescence polarisation immunoassay were included in these figures.

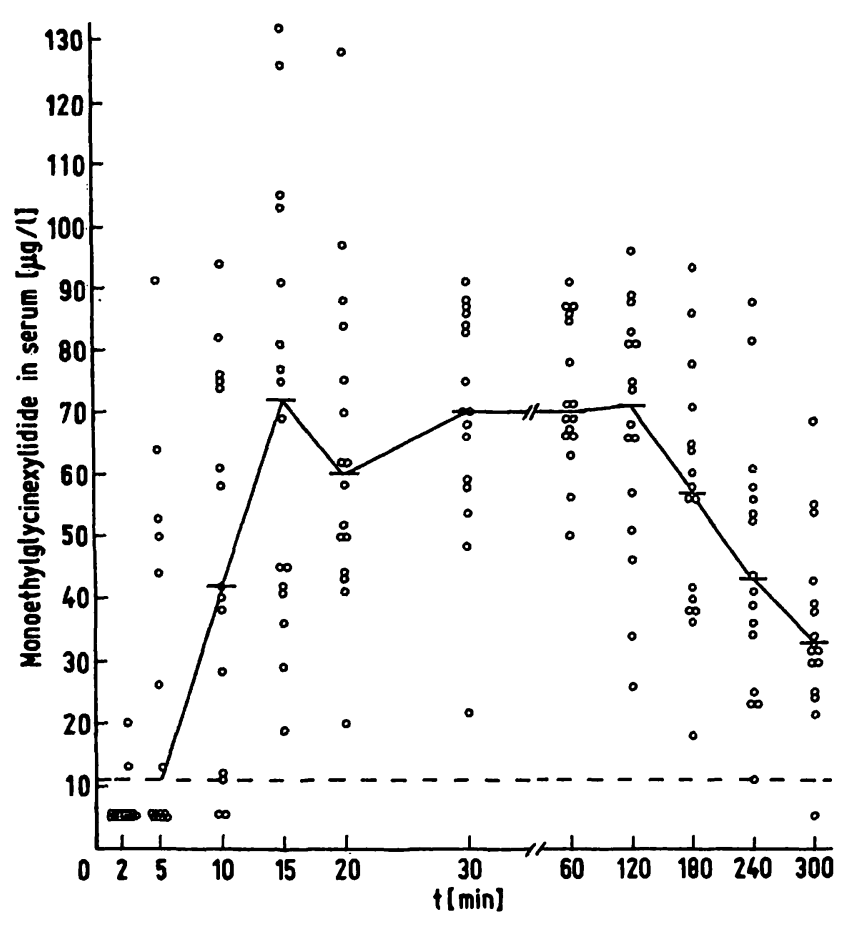

Fig. 5. Monoethylglycinexylidide concentrations in serum determined in 16 healthy volunteers after a single bolus injection of lidocaine hydrochloride $(1 \mathrm{mg} / \mathrm{kg})$. The dotted line marks the detection limit of the FPIA. The median values (horizontal bars) were used to generate an averaged concentration-time curve of monoethylglycinexylidide.

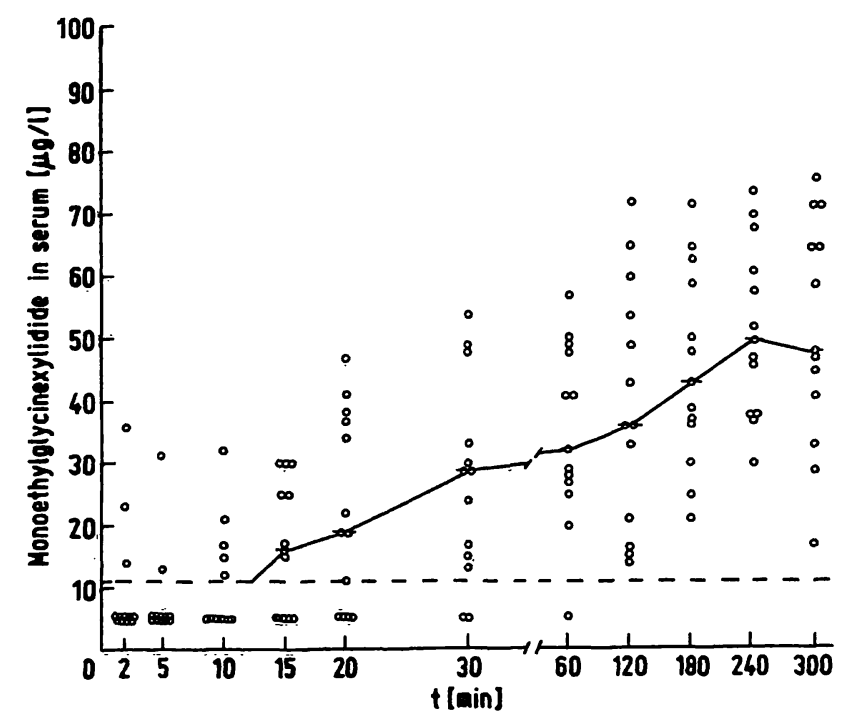

Fig. 6. Monoethylglycinexylidide concentrations in serum determined in 13 patients with liver cirrhosis after a single bolus injection of lidocaine hydrochloride $(1 \mathrm{mg} / \mathrm{kg})$. For further explanation see legend of fig. 5 .

There was a rapid increase of monoethylglycinexylidide concentration in serum within the first $15 \mathrm{~min}$ after lidocaine administration in normal subjects (fig. 5). The highest serum concentrations of this metabolite were measured $15 \mathrm{~min}$ after lidocaine injection. 


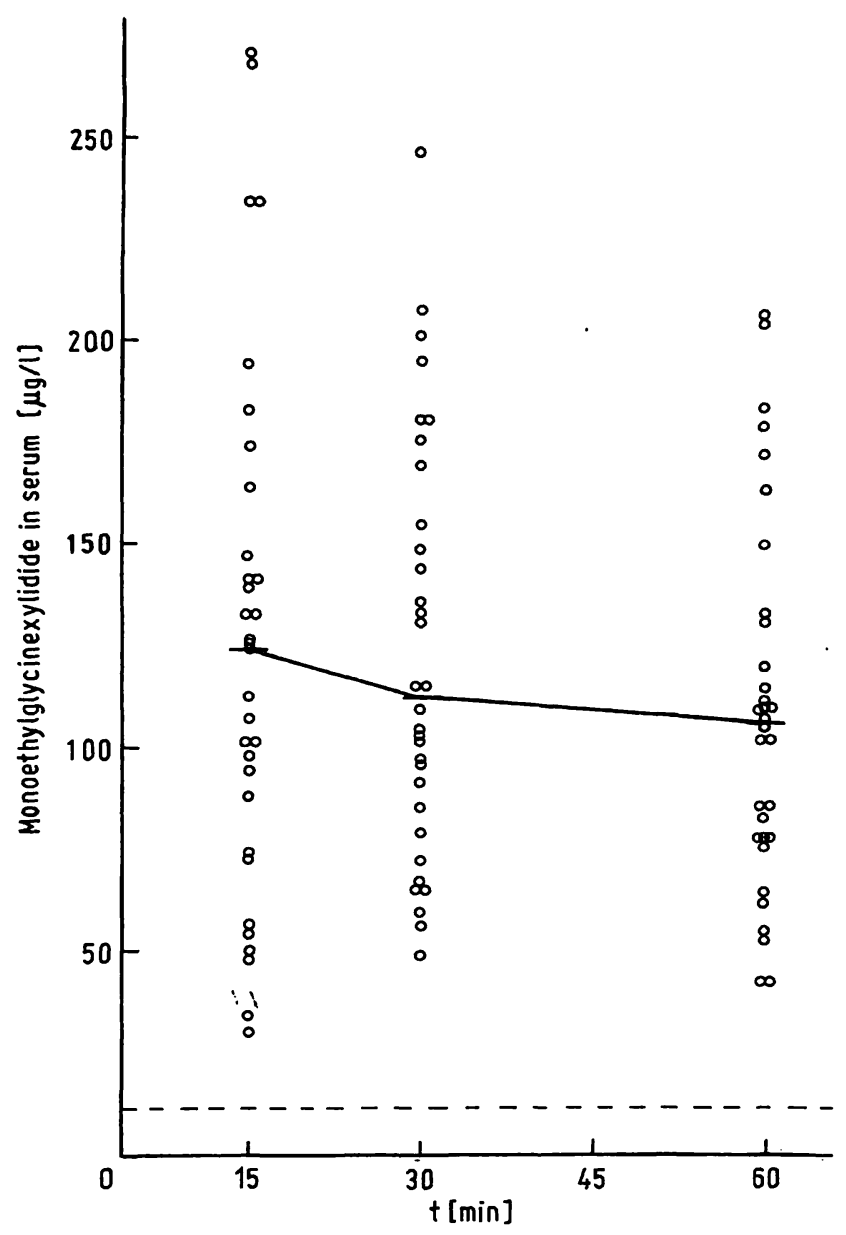

Fig. 7. Monoethylglycinexylidide concentrations in serum determined in 32 liver donors after a single bolus injection of lidocaine hydrochloride $(1 \mathrm{mg} / \mathrm{kg})$. For further explanation see legend of fig. 5 .

In one of the healthy subjects only relatively low monoethylglycinexylidide concentrations were observed. This subject excreted a relatively large amount of monoethylglycinexylidide within the first three hours after lidocaine injection $(94 \mu \mathrm{g}$ per $\mathrm{kg}$ body weight). In all the other healthy volunteers $(n=15)$ tested the average urinary excretion of monoethylglycinexylidide during this period was only $20.7 \mu \mathrm{g}$ per $\mathrm{kg}$ body weight (range: $2.0-45.0 \mu \mathrm{g} / \mathrm{kg}$ ).

In patients with liver cirrhosis the rate of monoethylglycinexylidide formation from lidocaine was substantially decreased (fig. 6). Therefore the averaged concentration-time curve observed in these patients was different from that obtained in healthy subjects. Within the first 15 minutes only very low serum concentrations of monoethylglycinexylidide were found. Maximal serum concentrations of this metabolite were observed at about 240 min after lidocaine injection. In these patients $(n=13)$ the average urinary excretion of monoethylglycinexylidide within the first 3 hours after lidocaine administration was only $4.0 \mu \mathrm{g}$ per $\mathrm{kg}$ body weight (range: $0.2-10.0 \mu \mathrm{g} / \mathrm{kg}$ ).
In fully rehabilitated liver recipients $(n=12)$, the 15 min monoethylglycinexylidide concentrations in serum (median: $97 \mu \mathrm{g} / \mathrm{l}$; range: $54-155 \mu \mathrm{g} / \mathrm{l}$ ) were in the range observed in normal subjects (fig. 5).

In liver donors, the average monoethylglycinexylidide concentrations in serum, determined 15,30 and 60 min after lidocain bolus injection, were significantly $(p<0.05)$ higher than the corresponding values obtained in normal subjects (fig. 5,7 ).

Figure 8 shows monoethylglycinexylidide concentrations in serum determined $15 \mathrm{~min}$ after i.v. lidocaine bolus injection in donors with normal liver histology, donors with altered liver histology, such as fatty changes or ballooning of hepatocytes, as well as in patients with histologically confirmed liver cirrhosis. Monoethylglycinexylidide concentrations in serum obtained with livers not transplanted because of their macroscopic appearance are represented as black triangles. Open diamonds indicate initial non-function after transplantation. Boxes delimit the 16th to 84 th

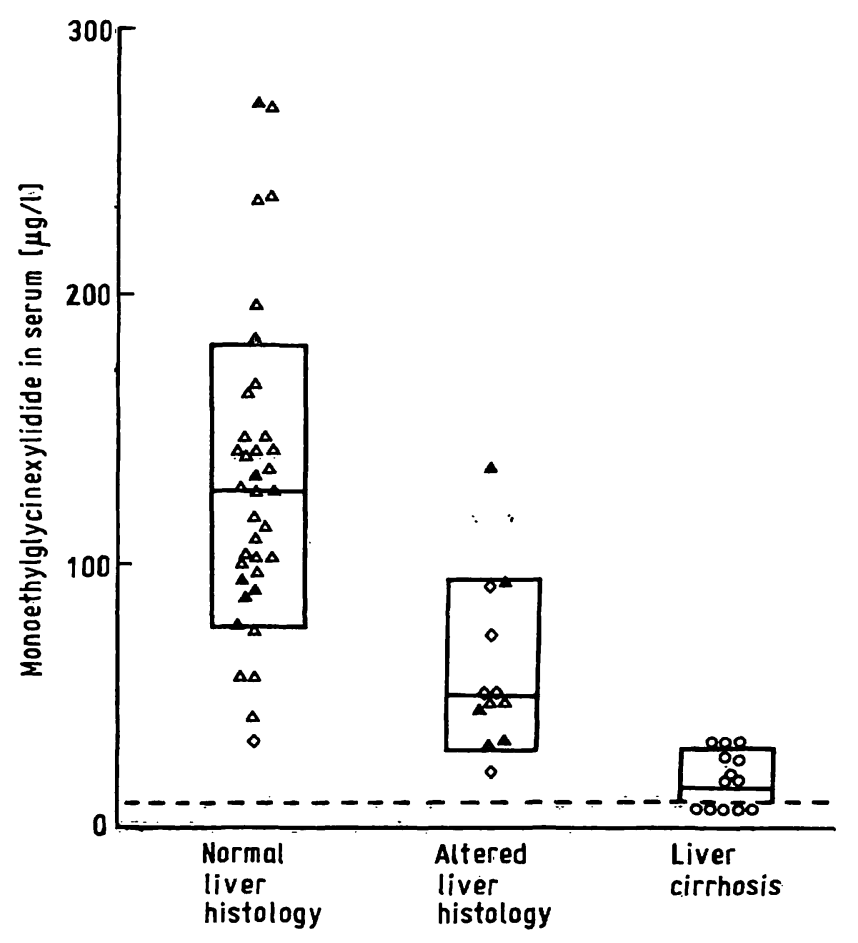

Fig. 8. Monoethylglycinexylidide concentrations in serum determined $15 \mathrm{~min}$ after a bolus injection of lidocaine hydrochloride $(1 \mathrm{mg} / \mathrm{kg})$ in donors with normal liver histology, donors with altered liver histology and patients with liver cirrhosis. Monoethylglycinexylidide concentrations in serum were determined for:

livers showing initial function following transplantation $(\triangle)$,

livers showing initial non-function following transplantation $(\diamond)$,

livers not transplanted because of macroscopic appearance $(\mathbf{\Delta})$,

livers of patients with liver cirrhosis (0).

Boxes delimit the 16 th to 84 th percentile. The median is indicated by the horizontal line in each box. The dotted line marks the detection limit of the FPIA. 
percentile ( 68 percent of values). The median is indicated by the horizontal line in each box.

Monoethylglycinexylidide concentrations in serum 15 min after i.v. lidocaine bolus injection were on average distinctly higher in donors with normal liver histology than in those with ballooning or fatty changes of hepatocytes and patients with liver cirrhosis. In 37 accepted organs, initial liver function and initial nonfunction were correctly predicted by means of monoethylglycinexylidide in 32 cases. Initial non-function of the liver following transplantation was observed 6 times. In four cases this event was correctly predicted by means of monoethylglycinexylidide.

Eleven donor organs were not transplanted because of their macroscopic appearance. Six out of eleven cases showed normal histology and normal monoethylglycinexylidide formation. In $3 / 11$ cases pathological findings of monoethylglycinexylidide and histology were observed. The remaining 2 cases had normal monoethylglycinexylidide values but pathological histology.

\section{Discussion}

The results of our study demonstrate that the described fluorescence polarisation immunoassay is suitable for determination of the low monoethylglycinexylidide concentrations present in serum after small lidocaine hydrochloride test doses of $1 \mathrm{mg}$ per $\mathrm{kg}$ body weight. A comparison of the results determined by fluorescence polarisation immunoassay with those obtained by high performance liquid chromatography showed a satisfactory correlation between both methods (fig. 4).

Our study on monoethylglycinexylidide formation kinetics confirms previous reports regarding the dependence of lidocaine elimination on liver function $(5,14,15)$. In general a monoethylglycinexylidide concentration in serum determined $15 \mathrm{~min}$ after a lidocaine bolus injection seems to reflect well the initial formation rate of this metabolite (fig. 5,6 ). So far, only one case has been encountered, in which the $15 \mathrm{~min}$ monoethylglycinexylidide concentration in serum was affected by an unusually high urinary excretion of this metabolite.

The monoethylglycinexylidide concentrations in serum, measured $15 \mathrm{~min}$ after lidocaine bolus injection, were on average significantly higher in liver donors than in normal subjects (fig. 5, 7). At present it may only be speculated that this phenomenon is due to an induction of lidocaine metabolism and/or an increased hepatic blood flow in donors caused by other therapeutically administered drugs.
As shown in figure 8 the monoethylglycinexylidide concentration in serum determined $15 \mathrm{~min}$ after a lidocaine test dose was a highly sensitive and specific indicator of hepatic damage. Measurement of initial monoethylglycinexylidide concentrations in serum allowed a satisfactory differentiation between the population of patients with liver cirrhosis and that of donors with normal liver histology. Monoethylglycinexylidide concentrations observed in donors with less prominent histological changes showed some overlap with the concentrations of monoethylglycinexylidide determined in both groups of donors with normal histology and patients with liver cirrhosis. More data are needed to define a meaningful "cut-off" value to distinguish between the presence and absence of liver damage. So far the "cut-off" has been empirically set at a monoethylglycinexylidide concentration in serum of $50 \mu \mathrm{g} / \mathrm{l}$, since concentrations below this value were generally associated with hepatic impairment (4).

Preliminary data on survival rates of recipients of primary liver transplants indicate that monoethylglycinexylidide formation may provide valuable prognostic information. A significant difference $(p<0.005)$ was observed in survival between recipients of allografts from donors with monoethylglycinexylidide concentrations in serum above $90 \mu \mathrm{g} / \mathrm{l}$ and those with concentrations of this compound below this value (16). Donor rating with normal or pathologic indocyanine green clearance as well as normal and pathologic galactose elimination capacity, however, failed to give satisfactory prognostic information. One to twelve years after transplantation, fully rehabilitated liver recipients showed $15 \mathrm{~min}$ monoethylglycinexylidide serum concentrations similar to those found in healthy volunteers.

Further evidence regarding the usefulness of the described approach for the assessment of liver function was recently obtained in a comparative study with various established liver function tests (e.g. indocyanine green clearance, galactose elimination capacity). It was demonstrated that a single monoethylglycinexylidide serum concentration determined in liver donors $15 \mathrm{~min}$ after intravenous administration of a lidocaine test dose had a distinctly higher predictive value for the assessment of primary non-function of the subsequently transplanted liver than all the other liver function parameters tested (4).

It appears that certain specific drug-metabolizing pathways are sensitive to hepatocellular injury. Based on N-demethylation, for example, an aminopyrine breath test was developed $(17,18)$, which permits the detection of even minor hepatic injuries. In a modification of this concept we have chosen monoethyl- 
glycinexylidide formation after lidocaine injection as indicator of liver function. It has been demonstrated that monoethylglycinexylidide formation depends mainly on hepatic cytochrome P-450-mediated Ndeethylation $(8,19)$. Since the parent drug lidocaine has an intermediate-high though variable hepatic extraction ratio (20), it has to be expected that the rate of monoethylglycinexylidide formation may be affected to a certain extent by major changes of hepatic blood flow. It has to be considered, however, that according to a study of Huet et al. (20), in patients with cirrhosis the disposition of lidocaine is scarcely influenced by hepatic blood flow and becomes limited by intrinsic clearance. So far, it is not known to what extent changes in the distribution volume of monoethylglycinexylidide can influence the $15 \mathrm{~min}$ concentration of this substance in serum. From our clinical experience, however, this factor is unlikely to have a negative effect on our test results, since a clear-cut separation of normal subjects and patients with histologically proven liver cirrhosis was possible by use of the 15 min monoethylglycinexylidide concentration in serum.

In a further study with liver donors the results of the monoethylglycinexylidide test were compared with those of indocyanine green clearance and galactose elimination capacity. A differentiation between normal and pathologic donor liver histology was only possible with the monoethylglycinexylidide formation test (16).

Lidocaine at the low doses used in our study appears to be a safe test compound. It has to be considered,

\section{References}

1. Paumgartner, G. (1975) Schweiz. Med. Wochenschr. 105, 5-30.

2. Tygstrup, N. (1966) Scand. J. Clin. Lab. Invest. 18 (suppl. 92), $118-125$

3. Makowka, L., Gordon, R. D., Todo, S., Ohkohchi, N., Marsh, J. W., Tzakis, A. G., Yokoi, H., Ligush, J., Esquivel, C. O., Satake, M., Iwatsuki, S. \& Starzl, T. E. (1987) Transpl. Proc. 19, 2378-2382.

4. Burdelski, M., Oellerich, M., Lamesch, P., Raude, E., Ringe, B., Neuhaus, P., Bortfeld, S., Kämmerling, C., Raith, H., Scheruhn, M., Westphal, C., Worm, M. \& Pichlmayr, R. (1987) Transpl. Proc. 19, 3838-3839.

5. Forrest, J. A. H., Finlayson, N. D. C., Adjepon-Yamoah, K. K. \& Prescott, L. F. (1977) Br. Med. J. 1, 1384-1387.

6. Oellerich, M. (1987) In: Funktion und Funktionsdiagnostik der Leber (Seidel, D. \& Lang, H., eds.) Heidelberg, Germany, Springer, pp. 53-55.

7. Keenaghan, J. B. \& Boyes, R. N. (1972) J. Pharmacol, Exp. Ther. $180,454-463$ however, that this substance can produce anaphylactic reactions (21). For liver donors or recipients, however, this problem is of relatively low singificance since these patients are closely monitored at intensive care units. So far in our study adverse reactions, other than slight drowsiness in patients with severe hepatic impairment, were not observed: In comparison with other liver function tests, such as the aminopyrine breath test (22) or bromosulphophthalein test (23), the risk of serious side effects appears to be considerably lower with the described lidocaine test.

The fluorescence polarisation immunoassay is rapid and easy to perform. A single serum sample from a patient can be analysed within about $20 \mathrm{~min}$. Therefore this assay is very convenient for the assessment of liver quality in potential donors, since the results can be made available early before transplantation. This aspect is of particular importance because histologically and functionally intact organs are often not transplanted because of macroscopic appearance. In our study we observed that $55 \%$ of the livers not accepted for transplantation because of macroscopic appearance would have been suitable for transplantation according to histology and the described lidocaine liver function test,

From the results of our study it is concluded that the analysis of hepatic monoethylglycinexylidide formation is a promising new approach for rapid assessment of hepatic function, particularly in liver donors. A prospective study is currently in progress at our hospital to further investigate the diagnostic and prognostic value of this test.

8. Pieper, J. A. \& Rodman, J. H. (1986) In: Applied Pharmacokinetics (Evans, W. E., Schentag, J. J. \& Jusko, W. J., eds.) 2nd ed., Applied Therapeutics, Inc., Spokane, pp. 639-681.

9. Thomson, A. H., Elliott, H. L., Kelman, A. W., Meredith, P. A. \& Whiting, B. (1987) J. Pharmacokin. Biopharm. 15, $101-115$.

10. Chan, C. \& Smith, C. M. (1984) Clin. Chem. 30, 1018.

11. Kaiser, H. (1965) Fresenius Z. Anal. Chem. 209, 1-18.

12. Nation, R. L., Peng, G. W. \& Chiou, W. L. (1979) J. Chromatogr. 162, 466-473.

13. Feldmann, Ü., Schneider, B., Klinkers, H. \& Haeckel, R. (1981) J. Clin. Chem. Clin. Biochem. 19, 121-137.

14. Thomson, P. D., Melmon, K. L., Richardson, J. A., Cohn, K., Steinbrunn, W., Cudihee, R. \& Rowland, M. (1973) Ann. Intern. Med. 78, 499-508.

15. Williams, R. L. \& Mamelok, R. D. (1980) Clin. Pharmacokinet. $5,528-547$. 
16. Burdelski, M., Oellerich, M., Raude, E., Lamesch, P., Ringe, B., Scheruhn, M., Raith, H., Westphal, C., Worm, M., Bortfeld, S., Schulz, M., Wittekind, C., Hoyer, P. F. \& Pichlmayr, R. (1987) Transpl. Proc. in press.

17. Lauterburg, B. \& Bircher, J. (1973) Gastroenterology 65, 556.

18. Hepner, G. W. \& Vesell, E. S. (1974) N. Engl. J. Med. 291, 1384-1388.

19. Pang, K. S., Terrell, J. A., Nelson, S. D., Feuer, K. F., Clements, M. J. \& Endrenyi, L. (1986) J. Pharmacokin. Biopharm. 14, 107-130.
20. Huet, P. M. \& Villeneuve, J. P. (1983) Hepatology 3, $913-$ 918.

21. Kennedy, K. S. \& Cave, R. H. (1986) Arch. Otolaryngol. Head Neck Surg. 112, 671-673.

22. Baker, A. L., Kotake, A. N. \& Schoeller, D. A. (1983) Seminars in Liver Disease 3, 318-329.

23. Wernze, H. (1979) In: Klinische Hepatologie (Kühn, H. A \& Wernze, H., eds.) Thieme-Verlag, Stuttgart, pp. 3.1633.168 .

Prof. Dr. M. Oellerich

Institut für Klinische Chemie

Medizinische Hochschule Hannover

Konstanty-Gutschow-Str. 8

D-3000 Hannover 61 
